\title{
A rapid identification method for severely earthquake-damaged areas based on damaged mobile phone base stations in China
}

\author{
Xiaoyong Zhang ${ }^{1} \cdot{\text { Qingshui } \mathrm{Lu}^{2} \cdot \text { Baokun Ning }}^{1} \cdot$ Zhiyong Huang $^{1}$
}

Received: 26 October 2015/ Accepted: 5 March 2016

(C) Springer-Verlag Berlin Heidelberg 2016

\begin{abstract}
Obtaining an accurate map of severely damaged areas immediately after an earthquake is a high priority in China. Previous methods of mapping these areas in the country have been too slow. The increasing number of mobile phone base stations provides a new means of identifying areas severely damaged by earthquakes in a very short time. In this study, we derive a new method based on the data of faulty mobile phone base stations. Our results show that areas of extreme earthquake damage identified according to base stations damaged by the Ludian and Lushan earthquakes were in very good agreement with large-magnitude seismic intensity zones outlined by the China Earthquake Administration. This indicates the reliability of our method, which can be used to help the government provide timely rescue after an earthquake and direct resources to high-priority areas.
\end{abstract}

Keywords Confidence ellipse $\cdot$ Earthquake $\cdot$ Extremely damaged area $\cdot$ Mobile phone base station

\section{Introduction}

Obtaining an accurate map of areas severely damaged by an earthquake within $2 \mathrm{~h}$ of its occurrence is a priority for the emergency command of the Chinese Government. This information is essential for saving lives and protecting

Qingshui Lu

qslu@yic.ac.cn

1 National Earthquake Response Support Service, Beijing, China

2 Yantai Institute of Coastal Zone Research, Chinese Academy of Sciences, Yantai 264003, Shandong, China property. However, current methods to map earthquakedamaged areas in China do not meet the required 2-h time constraint. For instance, seismic intensity attenuation models rely on seismic intensity in the earthquake epicentral region to identify extremely damaged areas, but acquiring seismic intensity data to determine that region requires many hours of processing (Yu 1995; Zhang et al. 2009; Tan et al. 2011). Some studies use earthquake aftershock data to estimate extremely damaged areas. However, with this method, processing the seismic data to derive a map of such areas requires at least 1 day because a series of aftershock data observed within $24 \mathrm{~h}$ after the main earthquake are required (Wu 1995; Han and Jiang 2010; Bai et al. 2011). Empirical statistical models can be used to rapidly map severely damaged areas, but the accuracy of such models is low (Xu et al. 2011).

United States of America (USA) Government developed the Shakemap system based on more than 3000 strong shake stations to obtain an earthquake intensity map within 3-5 min of an earthquake. This system has been used in many countries (Wald et al. 2003, 2008; Kaka and Atkinson 2005; Bragato 2009; Kiratzi 2011). The Japanese Government has built more than 4000 observation stations to record earthquake intensity. This network can locate severely damaged areas within 2-3 min of an earthquake (Katayama et al. 1988). At present, the number of seismic stations in China is very small, so the US or Japanese methods to identify severely damaged areas from existing observation systems cannot be used. In the present study, we explore a new method for mapping these areas within a very short time of the main shock.

The mobile phone base station is the basic unit of mobile communication services. With growth in the use of these services, the number of base stations is also increasing, forming a global communication network. Each 
base station serves as a geographic area called a cell. When an earthquake occurs close to the base station site, the station may be impaired because of damage to optical cables, power failure, or instruments. A faulty base station can serve as an indicator of damage in the earthquakeimpacted area. These faulty stations can be identified within $10 \mathrm{~min}$ of the earthquake, which meets the requirements of the Government Earthquake Rescue Command. Therefore, our objective was to develop a method for mapping severely damaged earthquake areas based on information of faulty mobile phone base stations. As a case study, we selected the Ludian earthquake of 3 August 2014.

\section{Data and method}

\section{Study area}

The extent of Ludian County is $27.0-27.53^{\circ} \mathrm{N}$, $103.0-103.7^{\circ} \mathrm{E}$ in northeastern Yunnan Province. It has a total area of $1519 \mathrm{~km}^{2}$ (Fig. 1) and a population of 385,700 . Mountains cover $87.9 \%$ of the county area, and $12.1 \%$ lies on a plain. The elevation ranges from 340 to $4027 \mathrm{~m}$. Ludian is near the Xiyu River-Zhaotong fault zone. The China mobile phone company has developed a network of mobile phone base stations covering the entire area. There have been several recent earthquakes in Ludian County. The latest earthquake was on 3 August 2014, with a magnitude of 6.5 (Zhao et al. 2014; Cheng et al. 2015).

\section{Data}

The data used include two main datasets. One is an earthquake intensity map from the China Earthquake Administration (www.cea.gov.cn). The second is locations of mobile phone base stations and faulty base stations after the 3 August 2014 earthquake. These locations included Ludian County and surrounding counties or cities, such as Qiaojia County, the city of Zhaotong, and Huize County. This dataset was obtained from the Ludian Branches of the China Mobile Phone Company.

\section{Method}

Powerful earthquakes often cause severe damage in a limited area. In our field surveys after several earthquakes, we found that base stations in extremely damaged areas were affected, but stations outside those areas experienced very little damage.

The shape of the extremely damaged area is approximated as elliptical or circular, so both shapes can be expressed by elliptical equations. Distances from one station to others around it are calculated, the k-Nearest neighbors algorithm is used to remove stations as outliers whose distances to nearby stations are larger than those of other points (Ismo 2004).The method for calculating confidence ellipses was used to estimate the severe damage area (Ding 1990).

The following variables were calculated using columns $X$ and $Y$, which are the longitude and latitude of damaged base stations:

$\operatorname{sum} x=\operatorname{sum}(x)$

$\operatorname{sum} y=\operatorname{sum}(y)$

$\operatorname{sum} x x=\operatorname{sum}(x \times x)$

$\operatorname{sum} y y=\operatorname{sum}(y \times y)$

$\operatorname{sum} x y=\operatorname{sum}(x \times y)$,

where $\operatorname{sum} x$ is the sum of $x$, sumy is the sum of $y, \operatorname{sum} x x$ is the sum of $x$ by $x$, sumyy is the sum of $y$ by $y$, and sumxy is the sum of $x$ by $y$. With these values, the means of $x$ and $y$ and variance and covariance were calculated as follows:

Fig. 1 Location of study area

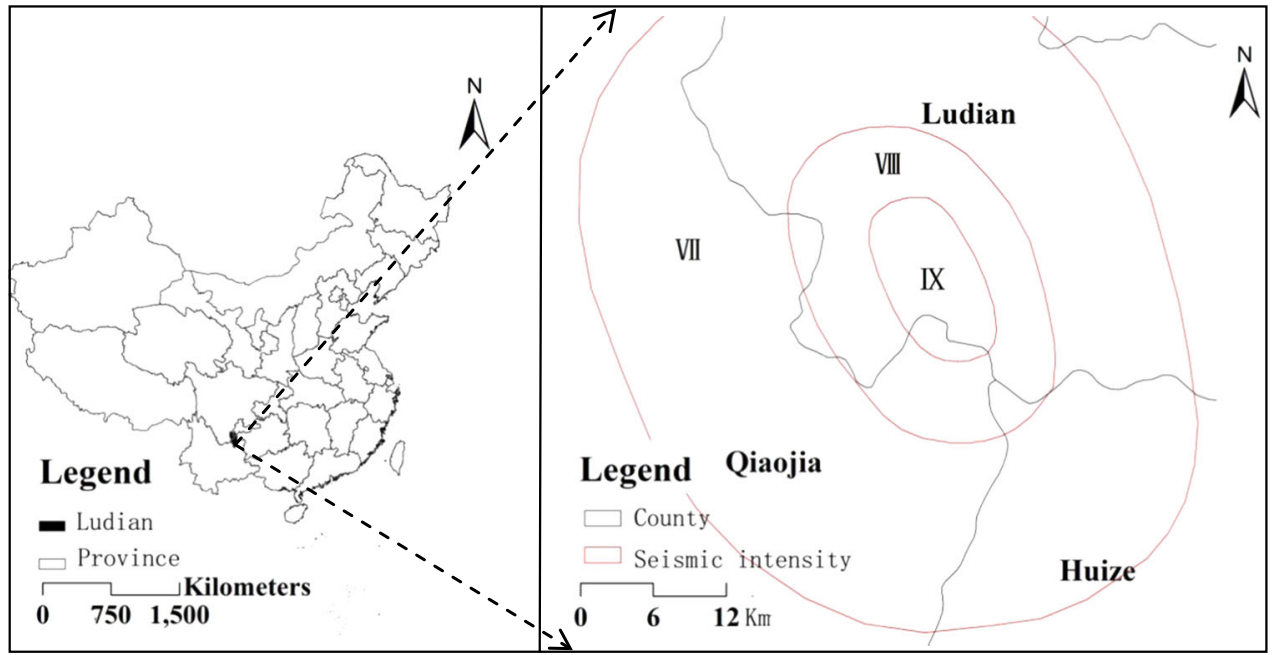




$$
\begin{aligned}
& x \text { bar }=\frac{\operatorname{sum} x}{n} \\
& y \text { bar }=\frac{\operatorname{sum} y}{n} \\
& \operatorname{var} x=\frac{\operatorname{sum} x x}{n} \\
& \operatorname{var} y=\frac{\operatorname{sum} y y}{n} \\
& \operatorname{covar} x y=\frac{\operatorname{sum} x y}{n},
\end{aligned}
$$

where $x$ bar is the mean of $x, y$ bar is the mean of $y$, var $x$ is the variance of $y, \operatorname{var} x$ is the variance of $x$, and covar $x y$ is the covariance of $x y$.

New columns are generated by the following equations:

$d x=x-x$ bar

$d y=y-y \mathrm{bar}$

$\operatorname{sum} d x d x=\operatorname{sum}(d x \times d x)$

$\operatorname{sum} d y d y=\operatorname{sum}(d y \times d y)$

$\operatorname{sum} d x d y=\operatorname{sum}(d x \times d y)$,

where $d x, d y, \operatorname{sum} d x d x$, sum $d y d y$, and sum $d x d y$ are new parameters generated by $x$ and $y$.

The angle at which the ellipse is "rotated" from the horizontal is calculated by the following:

$$
\begin{aligned}
& \text { theta }=0.5 \times \arctan \left(\frac{2 \times \operatorname{sum} d x d x}{\operatorname{sum} d y d y-\operatorname{sum} d x d x}\right) \\
& c=\cos (\text { theta }) \\
& s=\sin (\text { theta }) \\
& X \text { new }=c \times d x-s \times d y \\
& Y \text { new }=s \times d x+c \times d y \\
& \text { sum } \_X \text { new } X \text { new }=\operatorname{sum}(X \text { new } \times X \text { new }) \\
& \text { sum_Ynew } Y \text { new }=\operatorname{sum}(Y \text { new } \times Y \text { new }) \\
& \text { varXnew }=\frac{\text { sum_Xnew } X \text { new }}{n} \\
& \text { var } Y \text { new }=\frac{\text { sum_Ynew } Y \text { new }}{n} \\
& a=\text { sqrt }(\text { var } X \text { new }) \\
& b=\operatorname{sqrt}(\operatorname{var} Y \text { new }),
\end{aligned}
$$

where theta is the angle of ellipse rotation, $a$ represents length of the semi-major axes, $b$ is the length of the semiminor axes, $c, s, X$ new, Ynew, varXnew, and varYnew are parameters. Normally, this is for a $68 \%$ confidence ellipse, and the length of the semi-major axes and the semi-minor axes for a $95 \%$ confidence ellipse is determined by the following:
$A=2.3 \times a$

$B=2.3 \times b$

\section{Results}

Outliers were removed, and locations (latitude and longitude) of the faulty base stations within the zone of all stations damaged by the Ludian earthquake were used to calculate parameters of the confidence ellipse with Eqs. 1-28.

Therefore, the geometric center of the extremely damaged elliptical zone was $27.099^{\circ} \mathrm{N}, 103.360^{\circ} \mathrm{E}$ (Table 1 ). The long semi-axis of the $68 \%$ confidence ellipse is $5.42 \mathrm{~km}$, the minor axis is $4.48 \mathrm{~km}$, and the rotation angle is $120.47^{\circ}$ (Tables 2, 3). The long semi-axis of the $95 \%$ confidence ellipse is $12.45 \mathrm{~km}$ and the minor semi-axis is $10.30 \mathrm{~km}$.

Figure 2 shows a seismic intensity map of the 3 August 2014 Ludian earthquake produced by the China Earthquake Administration, and the ellipse outlining the severely damaged area estimated based on the faulty mobile phone base stations. Areas marked as zones of seismic intensity Mercalli-Cancani-Sieberg (MCS) VIII and IX represent those with severe damage. The total area predicted by our method using the $95 \%$ confidence ellipse is $402 \mathrm{~km}^{2}$, as compared with the actual area of $380 \mathrm{~km}^{2}$ according to the China Earthquake Administration (www.cea.gov.cn). The accuracy of the predicted area by our method using the $95 \%$ confidence ellipse is $95 \%$ (the percent of the predicted area by our method using the $95 \%$ confidence ellipse to the actual extremely damaged area), and our predicted severely damaged area nearly coincides with that determined by a field survey, demonstrating the accuracy of our predicted result.

\section{Discussion}

A mobile phone base station is composed of a machine room and an iron tower. Signal transmission is via twin channels. One is through optical fiber and the other is through communication satellites. Power is from a station storage battery, self-starting kerosene, and electric power. The station has some facility to determine its status and send a signal to the safety center to report this. Therefore, a

Table 1 Center location of derived ellipse for Ludian earthquake

\begin{tabular}{lll}
\hline & Longitude & Latitude \\
\hline Center position & $103.36^{\circ}$ & $27.099^{\circ}$ \\
\hline
\end{tabular}


Table 2 Derived semi-axis of confidence ellipse for Ludian earthquake

\begin{tabular}{lll}
\hline Confidence level & $68 \%$ & $95 \%$ \\
\hline Long semi-axis $(\mathrm{km})$ & 5.42 & 12.45 \\
Minor semi-axis $(\mathrm{km})$ & 4.48 & 10.30 \\
Area $\left(\mathrm{km}^{2}\right)$ & & 402 \\
\hline
\end{tabular}

Table 3 Rotation angle of confidence ellipse for Ludian earthquake

Rotation angle of confidence ellipse $120.47^{\circ}$

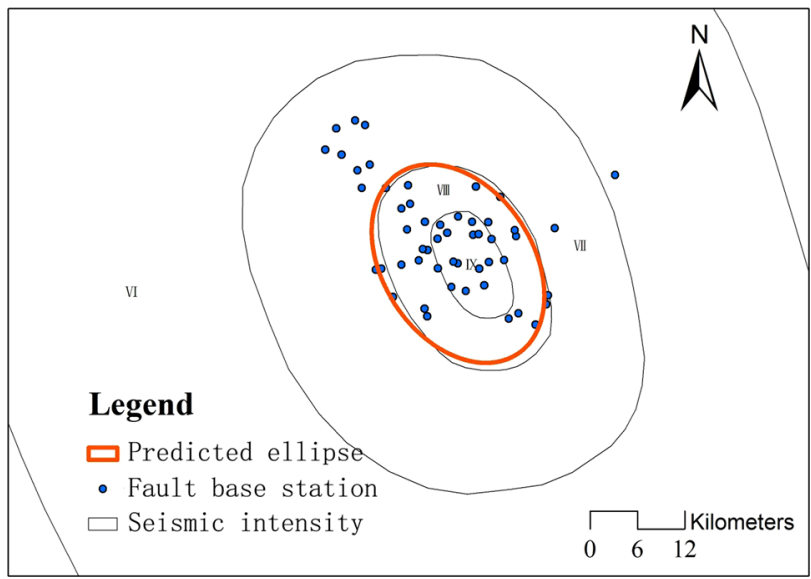

Fig. 2 Seismic intensity zones based on field data (black lines) and the estimated severe damage area (red line) of the Ludian earthquake

Table 4 Percentage of faulty base stations in seismic intensity zones

\begin{tabular}{lllc}
\hline Seismic intensity zones & IX & VIII & VII \\
\hline All base stations & 16 & 37 & 146 \\
Faulty base stations & 15 & 23 & 13 \\
Percent (\%) & 93.8 & 62.2 & 8.9 \\
\hline
\end{tabular}

faulty mobile phone base station can be immediately checked after earthquakes.

The relationship between the space distribution of faulty base stations and an isoseismic ellipse was analyzed. Damaged stations were mainly along a southwesterly direction, and this was also the direction of the long axis of the ellipse. The damaged area was separated into intensity zones. Percentages of damaged base stations to all stations in zones of macroseismic intensity MCS IX, VIII, and VII were $93.8,62.2$, and $8.9 \%$, respectively (Table 4 ). This shows that base stations suffered more severe damage in zones of larger intensity.

For a rough comparison with possible site effects, the base stations were put into three classes according to slope degree. There was no station with a slope $>45^{\circ}$ (Table 5). For stations with slopes $<15^{\circ}$, percentages of damaged stations to all stations in zones of seismic intensity MCS IX, VIII, and VII were 87.5, 46.2, and 7.2 \%, respectively. For stations with slopes $<30^{\circ}$, the corresponding percentages were 100, 71.4, and $11.9 \%$, respectively. For stations with slopes $<45^{\circ}$, the percentages were 100,50 , and $6.7 \%$, respectively. This indicates that the relationship between slope and damaged base stations is very low.

For additional verification of our proposed mapping method, we conducted another case study, from Lushan County in southwestern China. The magnitude 7.0 Lushan earthquake occurred on 20 April 2013 (Xu et al. 2013; Li et al. 2013). Locations of faulty mobile phone base stations were obtained from local mobile service companies, and the seismic intensity map was acquired from the China Earthquake Administration. Faulty base station outliers were eliminated. Then, parameters of the predicted ellipse were determined. The geometric center of the ellipse was $102.87^{\circ} \mathrm{E}, 30.11^{\circ} \mathrm{N}$ (Table 7). The long semi-axis of the $68 \%$ confidence ellipse was $17.66 \mathrm{~km}$, the minor semiaxis was $6.59 \mathrm{~km}$, and the rotation angle was $44.24^{\circ}$ (Tables $6,7,8$ ). The long semi-axis of the $95 \%$ confidence ellipse was $40.66 \mathrm{~km}$ and minor semi-axis was $15.17 \mathrm{~km}$. The area of the predicted $95 \%$ confidence ellipse was $1933 \mathrm{~km}^{2}$, compared with the actual area of extreme damage from a field survey of $1626 \mathrm{~km}^{2}$ (www.cea.gov. $\mathrm{cn}$ ). The prediction accuracy by our method using the $95 \%$ confidence ellipse (the percent of the predicted area by our method using the $95 \%$ confidence ellipse to the actual extremely damaged area) was $82 \%$.

Figure 3 shows the ellipse of extreme damage from the proposed method based on the mobile phone base stations, along with the seismic intensity map from the China Earthquake Administration. The zones of seismic intensity
Table 5 Percentage of faulty base stations in all slope classes

\begin{tabular}{|c|c|c|c|c|c|c|c|c|c|}
\hline \multirow{2}{*}{$\begin{array}{l}\text { Slope } \\
\text { (degree) }\end{array}$} & \multicolumn{3}{|l|}{ IX } & \multicolumn{3}{|c|}{ VIII } & \multicolumn{3}{|l|}{ VII } \\
\hline & All & Faulty & $\begin{array}{l}\text { Percent } \\
(\%)\end{array}$ & All & Faulty & $\begin{array}{l}\text { Percent } \\
(\%)\end{array}$ & All & Faulty & $\begin{array}{l}\text { Percent } \\
(\%)\end{array}$ \\
\hline $0-15$ & 8 & 7 & 87.5 & 13 & 6 & 46.2 & 69 & 5 & 7.2 \\
\hline $15-30$ & 6 & 6 & 100.0 & 21 & 15 & 71.4 & 59 & 7 & 11.9 \\
\hline $30-45$ & 2 & 2 & 100.0 & 2 & 1 & 50.0 & 15 & 1 & 6.7 \\
\hline Above 45 & 0 & 0 & 0 & 2 & 0 & 0 & 3 & 0 & 0 \\
\hline
\end{tabular}


Table 6 Derived semi-axis of confidence ellipse for Lushan earthquake

\begin{tabular}{lrr}
\hline Confidence level & $68 \%$ & $95 \%$ \\
\hline Long semi-axis $(\mathrm{km})$ & 17.66 & 40.66 \\
Minor semi-axis $(\mathrm{km})$ & 6.59 & 15.17 \\
Area $\left(\mathrm{km}^{2}\right)$ & & 1933 \\
\hline
\end{tabular}

Table 7 Center location of derived ellipse for Ludian earthquake

\begin{tabular}{lll}
\hline & Longitude & Latitude \\
\hline Center position & $102.87^{\circ}$ & $30.11^{\circ}$ \\
\hline
\end{tabular}

Table 8 Rotation angle of confidence ellipse for Lushan earthquake Rotation angle of confidence ellipse $44.24^{\circ}$

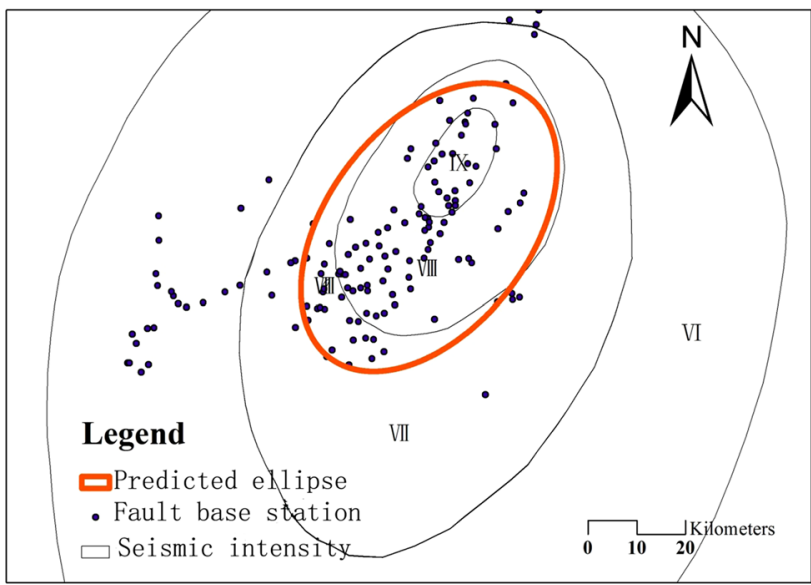

Fig. 3 Seismic intensity zones based on field data (black lines) and estimated zone of extreme damage area (red line) of Lushan earthquake

MCS VIII and IX cover an area similar to that of the ellipse calculated for the extreme damage area. Agreement between the two areas is not as strong as in the case of the Ludian earthquake, but is still very close. Calculated ellipses for the extremely damaged areas in both earthquakes show that our method produces very reliable results and can be used to identify severely damaged areas from other earthquakes immediately after their occurrence.

\section{Conclusions}

Based on data of mobile phone base stations damaged by earthquakes, we developed a new method of identifying areas of extreme damage. The method was then applied to data collected from the Ludian and Lushan earthquakes, and extremely damaged areas were identified. Very good agreement was found between the identified areas and seismic intensity data of the China Earthquake Administration, indicating that our method can be reliably used to rapidly identify extremely damaged areas following earthquakes. Such information will help governments to provide timely earthquake rescue and direct resources to high-priority areas.

Acknowledgments This work was supported by the Earthquake Science and Technology Spark Plan Project (XH14059), the National Natural Science Foundation of China (41301596), and the Science and Technology Project of Yantai (2012132). Thanks to Yan Cai in Zhaotong College of Yunnan Province and to an anonymous reviewer's great help.

\section{References}

Bai XF, Dai YQ, Li YQ, Zhu YF, Bai SD, Li JM (2011) Rapid assessment of the macro-epicenter and earthquake-effected field based on aftershocks: a case study of yunnan area. J Seismol Res 34(4):525-532 (In Chinese, with English Abstract)

Bragato PL (2009) Assessing regional and site-dependent variability of ground motions for ShakeMap implementation in Italy. Bull Seismol Soc Am 99(5):2950-2960

Cheng J, Wu Z, Liu J, Jiang C, Xu X, Fang L, Yang T (2015) Preliminary Report on the 3 August 2014, Mw 6.2/Ms 6.5 Ludian, Yunnan-Sichuan Border, Southwest China, Earthquake. Seismol Res Lett 86(3):750-763

Ding J (1990) Discussion on confidence ellipse. Bull Surv Mapp 1990(4):21-23 (In Chinese)

Han WB, Jiang GF (2010) Study on the relation between Isoseismic Line,aftershock area of strong earthquakes and their Seismotectonic environments. Earthquake 30(4):32-39 (In Chinese, with English Abstract)

Ismo K (2004) Outlier detection using k-nearest neighbor graph. IEEE 2004:430-433

Kaka SI, Atkinson GM (2005) Empirical ground-motion relations for ShakeMap applications in southeastern Canada and the northeastern United States. Seismol Res Lett 76(2):274-282

Katayama T, Sato N, Saito K (1988) SI-sensor for the identification of destructive earthquake ground motion. In Proceedings of the 9th World Conference on Earthquake Engineering, 7, p 667-672

Kiratzi A (2011) The 6 September 2009 Mw5. 4 earthquake in Eastern Albania-FYROM Border: focal mechanisms, slip model, ShakeMap. Turk. J. Earth Sci 20(4):475-488

Li Z, Tian B, Liu S, Yang J (2013) Asperity of the 2013 Lushan earthquake in the eastern margin of Tibetan Plateau from seismic tomography and aftershock relocation. Geophys J Int 195(3):2016-2022

Tan M, Li S, Sun J, Wang W, Tang LH, Wu CY (2011) The parameter fitting of earthquake intensity attenuation relationship model in Xinjiang. Inland Earthq 25(1):29-35 (In Chinse, with English Abstract)

Wald D, Wald L, Worden B, Goltz J (2003) ShakeMap, a tool for earthquake response (No. 087-03)

Wald D, Lin KW, Porter K, Turner L (2008) ShakeCast: automating and improving the use of ShakeMap for post-earthquake decision-making and response. Earthq Spectra 24(2):533-553

Wu KT (1995) Hazard Assessment of strong earthquake aftershock. China Earthquake 11(4):368-373 (In Chinese) 
Xu GD, Yuan Y, Fang WH, Shi PJ (2011) Fast loss assessment of M7.1 Yushu earthquake. J Earthq Eng Eng Vib 31(1):114-123 (In Chinese, English Abstract)

Xu X, Wen X, Han Z, Chen G, Li C, Zheng W, Liang M (2013) Lushan M S7. 0 earthquake: a blind reserve-fault event. Chin Sci Bull 58(28-29):3437-3443

Yu SJ (1995) Analyzing the Intensity attenuation in east and northwestern China. Acta Seismol Sin 17(2):203-211 (In Chinese)
Zhang Y, Ma G, Shi BP, Zhang J, Yang Y (2009) Development of seismic intensity attenuation model in North China and its application to quantitative estimation of earthquake location and magnitude. Acta Seismo Llogica Sinica 31(3):290-306

Zhao X, Liu J, Fen W (2014) The kinematic characteristics of the M S 6.5 Ludian Yunnan earthquake in 2014. Seismol Geol 36(4):1157-1172 